\title{
Evaluation of the Physical Fitness Level in Physical Education Female Students Using "Eurofit-Test"
}

\author{
Ružena Popović ${ }^{\text {, Aleksandra Aleksić }}{ }^{\text {, Darko Stojanović }}{ }^{1}$, Milena Stefanović ${ }^{1}$, Sara Božić ${ }^{1}$, \\ Miloš Popović ${ }^{2}$
}

${ }^{1}$ Faculty of Sport and Physical Education, University of Niš, Niš, Serbia

${ }^{2}$ Faculty of Sport and Physical Education, University of Pristine, Leposavić (Kosovo), Serbia

\section{Email address:}

ruzena@fsfv.ni.ac.rs (R. Popović), axy_gym@yahoo.com (A. Aleksić), darko89_nish@hotmail.com (D. Stojanović), milenastefanovic06@gmail.com (M. Stefanović), sarabozicnis@yahoo.com (S. Božić), popovicmilos1983@yahoo.com (M. Popović)

\section{To cite this article:}

Ružena Popović, Aleksandra Aleksić, Darko Stojanović, Milena Stefanović, Sara Božić, Miloš Popović. Evaluation of the Physical Fitness Level in Physical Education Female Students Using "Eurofit-Test". International Journal of Sports Science and Physical Education. Vol. 6, No. 1, 2017, pp. 1-15. doi: 10.11648/j.ijsspe.20170201.11

Received: October 30, 2016; Accepted: December 21, 2016; Published: February 23, 2017

\begin{abstract}
This work is based on the results of Cross-sectional experimental study results, which was implemented in StudyYear 2015/2016 within female students of the third year of Basic Academic Studies (BAS) at the Faculty of Sport and Physical Education (FSPE), University of Niš. This pilot study is for the first time realized with application of "Eurofit-Test" by [1] during the course of Rhythmic gymnastics (RG), on the end of sixth semester of the study year 2015/2016 (3+3 classes weekly / 45+45 Theory + Practice in Total/per semester). The testing was carried out in the framework of the teaching practice, as one of the pre-exam requirement, based on which the student can achieve a maximum 10 out of 60 possible points. Other pre-exam obligations include the mandatory RG compositions, implemented in form of three practical exams, followed by seminar work, regular presence at the theoretical and practical lessons, including lectures with bonus points for interactive teaching. The total sample of examinees includes $28 \mathrm{PE}$ female students especially selected at the entrance exam course (as compared to the assumed above average motor status), turned them into the regular curriculum in accordance with the Bologna Declaration. For the purpose of this study nine items of the "Eurofit-Test" battery was applied in regard to the physical fitness status evaluation. The research results were compared within the sample of PE female student's and analyzed as individual case studies and Total sample with the graphical presentation of the Figures for each test item separately.
\end{abstract}

Keywords: Eurofit-Test, Physical Education Female Students, Fitness Evaluation, Case-Studies

\section{Introduction}

In previous researches have been paid enough attention to the development, or estimation of somatic and physical abilities in all stages of age. Some authors are most often opted for occasional samples of respondents aged up 11 to 17 years of age.

Usually, those were the individual studies, but also was realized a monograph study of the national interest by [9] in former Yugoslavia, within the particular Republic centers, as well as academic and educational institutions (Primary and Secondary schools).

In that time, standardized battery of tests, has been applied for the assessment of the body composition by International Biological Program (IBP), and the basic motor abilities tests battery on the representative samples of respondents of nonpair ages $(11,13,15$, and 17 years old), in the context of higher graders of primary school students and secondary school students.

However, the battery like this could not provide all necessary answers, while the research results of our population could not be adequately compared with the research results of population in other countries in region and wider, or with research results conducted in EU, other European countries and in the world, as well.

The Group of experts for the Physical education and Sport at Council of Europe by [5], and [6], have provided the new evaluation system through the standardized battery of tests named Eurofit-Test, which eliminate common testing problems in the past and creates preconditions for the 
establishment of new norms which are adjusted to the specific selected samples of respondents according to age, gender, professional or sports orientation and ethnic of origin.

\subsection{Issue}

The study of Physical education and Sport, both in our country and in the region, EU, and other European and world countries, requires students with significant general, as well as specific predispositions (abilities, skills). This also applies to certain subjects of study requiring possession of the specific skills (within Physical, Musical, and Art education). In the area of Sport and PE, and its specific disciplines, there are some essential problems in the selection of candidates for study in the context of personnel schools:

- With what level of somatic and motor preconditions candidates apply for the study registration in the field of physical education and sport?

- With what level of somatic and motor preconditions are studies finished at the appropriate personnel schools?

- What kind of somatic and motor precondition should students fulfill with respect to universality and specificity of studies, in the time of the enrollment in the high education institution?

\subsection{Motor Development of the Higher-Education Youth}

Life expectancy in terms of development can be divided in multiple developmental periods. Because each person is unique and has own individual and specific traits of development, it is not possible to accurately and objectively explain different periods. Similar individual-specific differences exist in terms of gender, ethnicity and country of origin. For these reasons of grouping, or developmental classification of individuals, within a period that could be considered as a pre-determined agreement, individual authors or groups of experts from different scientific fields should look for a consensus.

From the point of this pilot study orientation, which was implemented on a sample of the higher education population, it was of the greatest interest studying the development of motor skills in adolescence (16-20 years), as well as during the period of young adulthood (21-30 years). Both of these periods have own specifics. Kasa, 2000 [7] states that at the end of this period, one individual complete their physical and spiritual maturation and becomes a young adult man or woman. Physical development practically ends during this period.

Ossification and bone growth are completed. Bodily proportions receive its final appearance. Secondary sexual characteristics are finishing their development. All internal organs are developing their final function. The movement of the body is consistent, the coordination of the whole body achieves harmony, and movement efficiency reaches its maximum value.

It should be noted that at this point, psychological development of the individual ends as well. This means that all mental processes reach their full value. The development of movement skills, especially physical fitness (strength, speed and endurance) reaches a maximum value in this period, for people who are engaged in regular physical activity. At the 18-20 years of age, individual have achieved the highest point of motor development, power is the most strongly developed after 14 years of age, and slows down after 18 years of age. A young man of 20 years of age manifests the typical indicators of health, which is further influenced by the development and improvement of movement skills, possibly stagnate or decrease due to inactivity.

The differences in motor skills are conditioned by profession of an individual, movement regime, training, lifestyle, self-discipline and the like. It should be noted that the differences in motor skills between boys and girls in this period are very evident. That is caused by differences in the anatomy of the body, functional ability and psychological sphere. For example, the muscle strength of women reaches an average of $63 \%$ of the power of a man. The women of the general population in this developmental period show a lower level of expression of every individual achievement, as compared to men. They are equal to the men only in the speed of movement frequency, of the different parts of the body, and exert a greater value only in terms of grow of flexibility.

In the human locomotion, such as jumping, throwing, shooting and other body activities, women significantly lag behind the men. Even in the period of puberty, the development of motor achievements is noticeably delayed in the female population. Motor achievement in regularly trained men improves to 18-19 years of age, after which the improvement is substantially reduced. Of course, it depends on what kind of training intensity is the person loaded. In individual who train regularly or participate in sports, results are improving after 20 years of age as well. Gender differences in achievement are recorded also according to sports orientation and specialization. Only results achieved in coordination within women and men are equal.

\section{Methods}

\subsection{Sample}

Includes 28 healthy female persons in Total, of special selected sample (in regard to the assumed above average motor status), which are participating in regular High Education Study Curriculum in the frame of the $3^{\text {rd }}$ year of study according to the Bologna Declaration.

For the needs of this study "Eurofit-Test" by [1] was applied, for the first time, on sample of PE female students, 22 years of age and older.

The study was implemented on the end of summer semester, of the $3^{\text {rd }}$ study year of the Basic-AcademicStudies, (2015/2016) with collaboration of PhD students of the Faculty of Sport and Physical Education, University of Niš, and supervised by the corresponding teacher.

\subsection{Procedure}

Eurofit-Test. Collection of nine (9) tests that covers 
flexibility, speed, agility, endurance and strength. Test battery is a standardized and designed by the Council of Europe, by [5], [6], for the school children and has been used in many European schools since 1988. It is designed in manner that testing can be completed within 35-40 minutes, using very simple equipment. Those tests items are:

(1) Flamingo (FLB) - Balance Test; (2) Plate-Taping Test (PLT) - Preferred hand speed frequency; (3) Sit-and-Reach Test (SAR) - Flexibility; (4) Standing Long Jump Test (SLJ) - Explosive strength; (5) Dominant Hand-grip Test (DHG) Isometric strengths; (6) Sit-Ups Test (SUP) - Abdominal Muscles Repetitive Strength; (7) Flexed Arms hand-grip Hang (FAH) - Arms and Shoulders Isometric Strength; (8) Run between cones (10x5m) - Agility test; (9) "Beep test" 20m-Taps-Run (CRT) - Cardio-Respiratory-Endurance.

\subsection{Data Analysis}

Based on realized testing, individual and group PE female students results are presented in form of two bar-charts (X-Yaxe); in the first bar-chart 4-levels are noted: MIN-MAX AVERAGE, and OWN result. In the second bar-chart all PE female students' results are presented as diagram, and placed in equidistant segments (fitness zones).

In majority of cases the results were placed in five segments, where normal dispersion of results was recorded. In particular test, because of the high results dispersion, there was a need to placed results in more levels (nine), as we can see in presentations below (Chapter 3). In majority of cases the results were placed in five segments, where normal dispersion of results was recorded. In a particular tests, because of the high results dispersion, there was a need to place results in more levels (nine), as we can see in presentations below (in Chapter 3).

\section{Results}

The Comparative analysis of the case studies has been used for the evaluation of estimated differences among measured PE female students within sample, with calculation of the AVERAGE, and presentation of MIN and MAX values, OWN student's score, as well as individual student's performance in the frame of the total sample results, and Fitness-Zones.

\subsection{Case Study - Flamingo - Balance-Test (FLB)}

This test estimates the ability to keep balanced position in harder circumstances (standing on dominate leg). For the good balance performance, except good development level of vestibular apparatus, the strength of the lower extremities is necessary as well as high level of ability to concentrate.

This test item was measured 3-times, and the best score was considered as test result. In the following Figures (1-2) are presented: Milena Stefanović's OWN result $(5.14 s)$, evidenced MAX (135.5s), and MIN (1.2s) values and recalculated AVERAGE $(13.26 s)$ value of the Total sample.

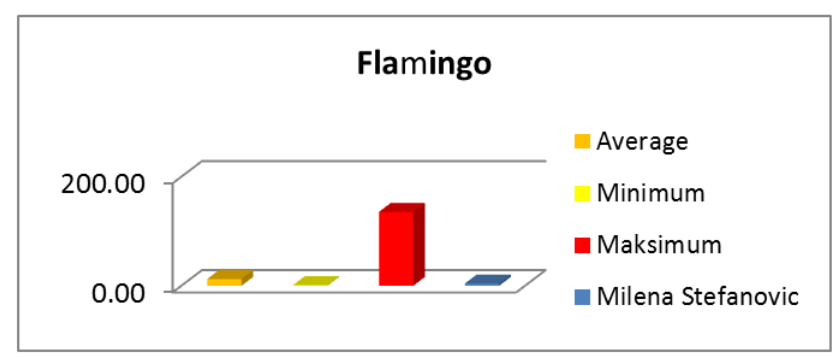

Figure 1. Flamingo Balance Test (FLB) - AVERAGE-MIN-MAX-OWN

Legend-1: AVERAGE (13.26s), MIN (1.2s), MAX (135.5s), OWNStudent's score $(5.14 \mathrm{~s})$.

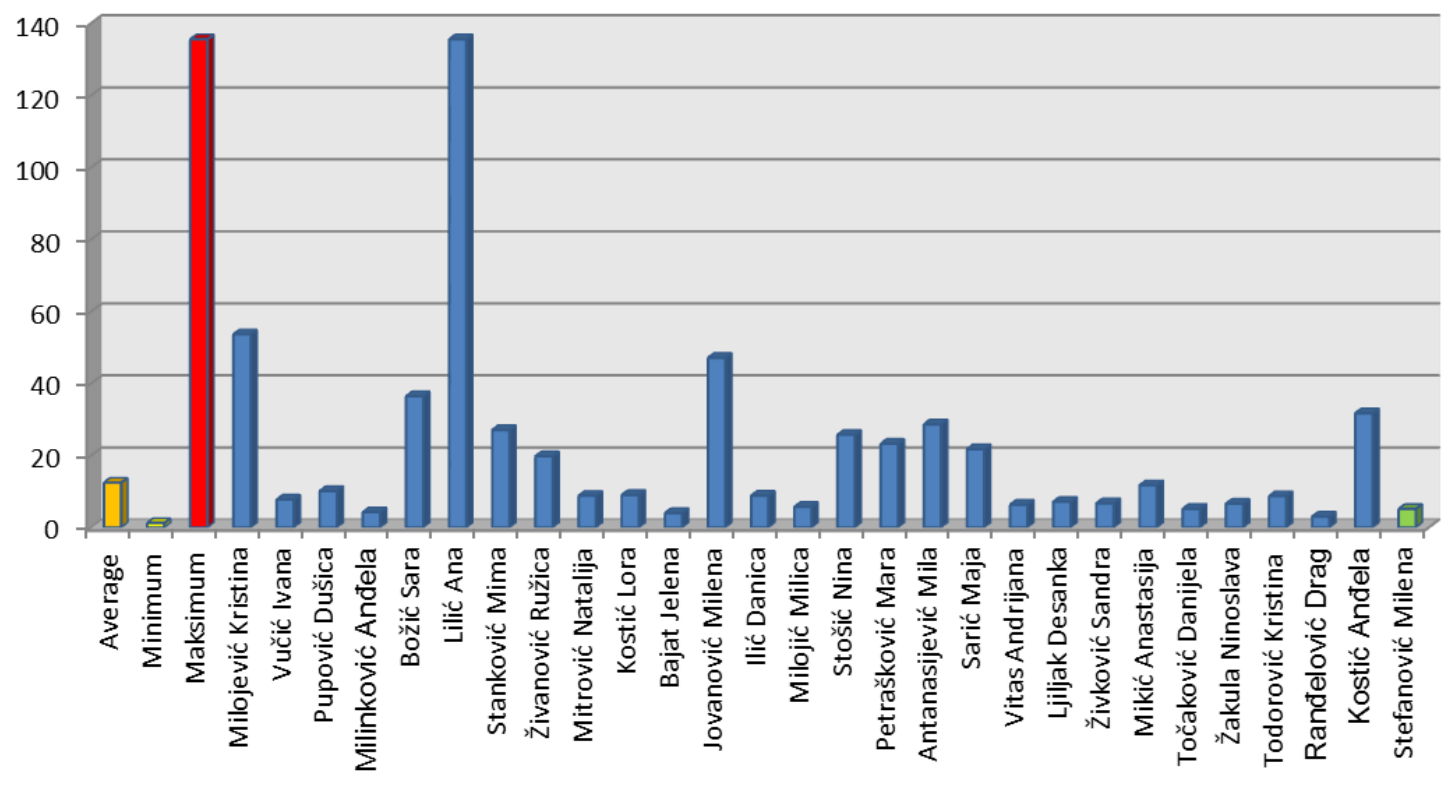

Figure 2. Flamingo Balance Test (FLB) - Diagram of the PE Female students Total sample results. $\square$ Average

$\square$ Minimum

- Maximum

- Students

$\square$ Stefanović Milena 


\subsection{Case Study-Plate-Tapping-Test (PLT)}

This test evaluate the speed of preferred hand frequency, in limited time ( 25 cycles/per $30 s)$, and the task is performed on the special shaped horizontal plate. On the base of the testing provided, individual students results are presented in form of two Figures: (3), and (5), for the 7-levels rating results (Total sample). Milena Stefanović's OWN-score (11.24 s) is placed in the above average fitness zone, between MAX (13.34 s), and AVERAGE value $(12.43 s)$, and MIN value is (8.43 s), Figure (3). The results represent inverse values* (which means that minimal value is de facto the best result).

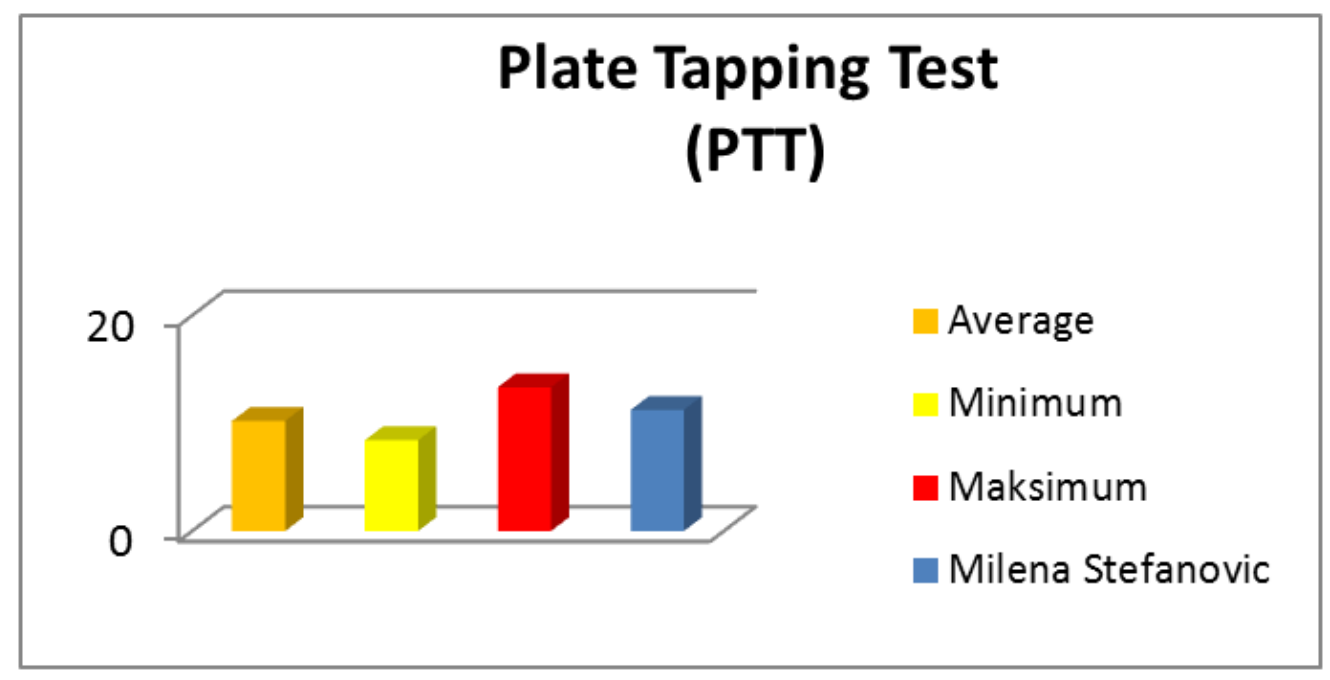

Legend-3: AVERAGE (10.15s); MIN (8.43s); MAX (13.34s); OWN-Student's score (11.24 s), * inverse value

Figure 3. Plate-Tapping-Test* (PLT) - AVERAGE-MIN-MAX-OWN.

On the Figure (6) results of all other female students are presented, and placed in particular equidistant segments (fitness zones), which is in this test distributed in ten segments, because of the relatively high results dispersion.

\subsection{Case Study - Sit and Reach Test (SAR)}

This test evaluates hip-joint flexibility and the lower extremities back muscles longevity in sitting position. The task is performed on the special shaped horizontal plate, marked with centimeter band. On the base of testing performed, PE female students results are presented in form of two Figures: (4), and (6), and on the Figure (4), 4-levels are presented, as explained in Legend-4, below.

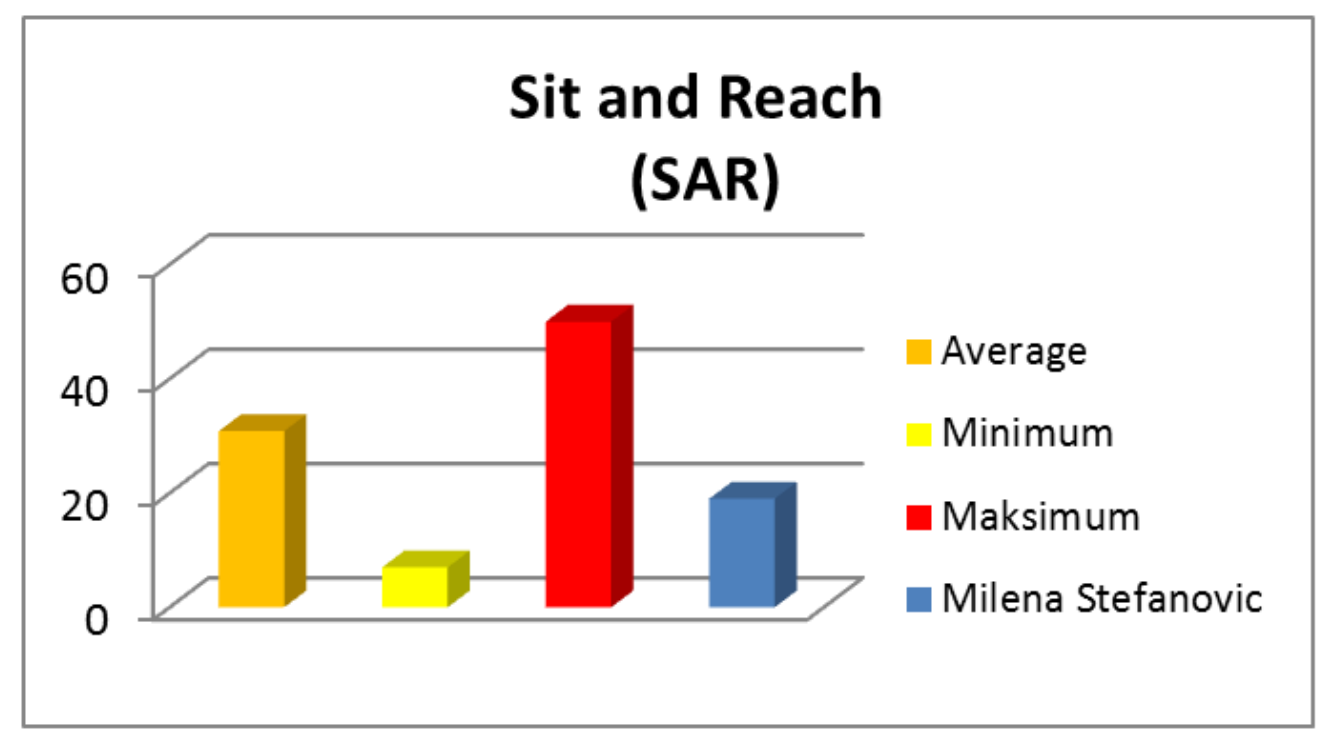

Legend-4: AVERAGE $(30.83 \mathrm{~cm}), \operatorname{MIN}(7.2 \mathrm{~cm}), \operatorname{MAX}(50 \mathrm{~cm})$, OWN- Student's score $(19 \mathrm{~cm})$

Figure 4. Sit and Reach Test (SAR) - AVERAGE-MIN-MAX-OWN.

On the presented Figures: (4), and (6) it is evident that the OWN-student's result $(19 \mathrm{~cm})$ is placed in the zone between MIN $(7.2 \mathrm{~cm})$, and AVERAGE value $(30.83 \mathrm{~cm})$ of the all other PE female students, MAX value is $(50 \mathrm{~cm})$. 


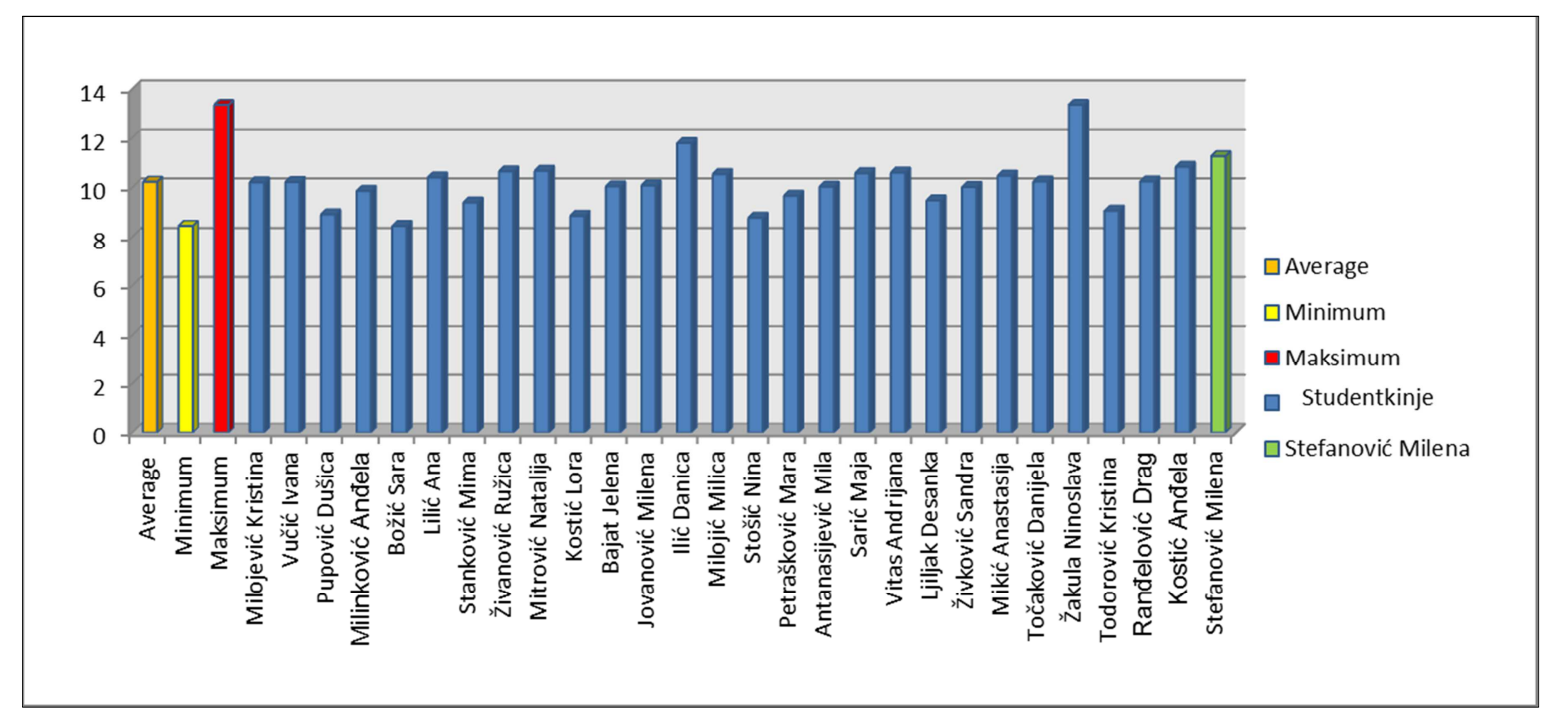

Figure 5. Plate Tapping Test (PLT) - Diagram of the PE Female students Total sample results.

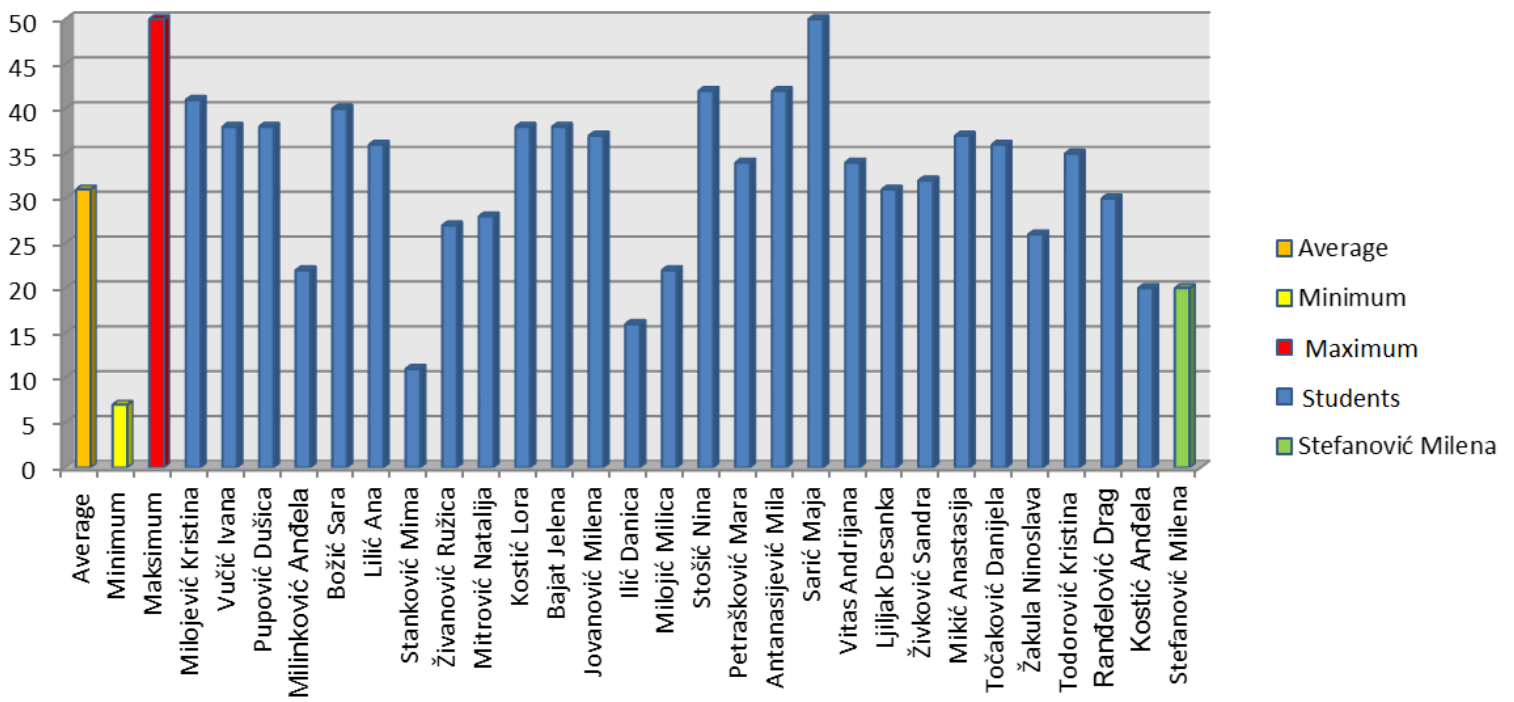

Figure 6. Sit and Reach Test (SAR) - Diagram of the PE Female students Total sample results.

\subsection{Case Study - Standing-Long-Jump (SLJ)}

This test estimates explosive power of lower extremities, or the ability to mobilize maximal amount of muscles units in one motion. For the high performance, except appropriate developmental level of legs muscles potential, there is need for to unifying the whole body coordination, considering hand movement, take-off, air movement and landing position, with high level ability of concentration. On the base of testing performed, the PE female students results are presented in form of Figures (7-8) and in Figure (7) 4-levels are presented, as explained in Legend-7 below.

On the Figure (8) results of the all other PE female students are presented, placed in five equidistant segments (fitness zones), while results dispersion is not very high. On the presented bar-chard, it is evident that the OWN Milena Stefanović's score $(176 \mathrm{~cm})$ is placed in the below average fitness zone, between MIN-value $(138 \mathrm{~cm})$, and AVERAGE- value $(189 \mathrm{~cm})$ of the all other PE female students, and MAX-value is $(234.5 \mathrm{~cm})$.

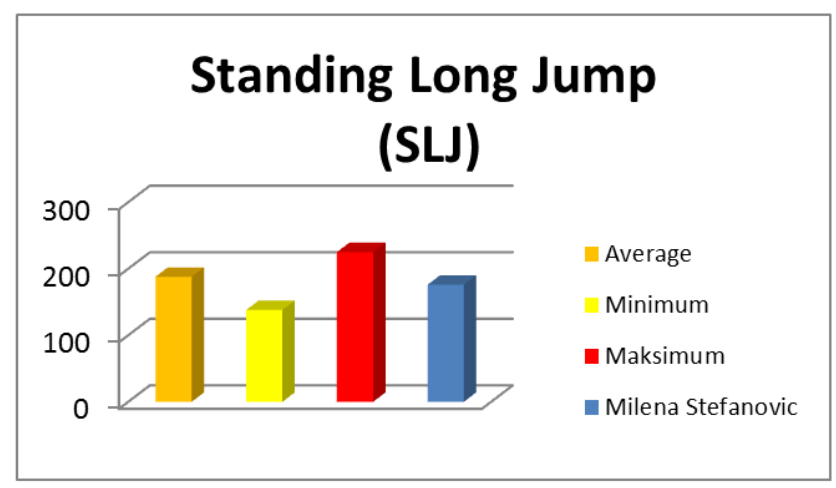

Figure 7. Standing Long Jump (SLJ) - AVERAGE-MIN-MAX-OWN.

Legend-7: AVERAGE $(189 \mathrm{~cm})$, MIN $(138 \mathrm{~cm})$, MAX $(234.5 \mathrm{~cm})$, OWNStudent's score $(176 \mathrm{~cm})$. 


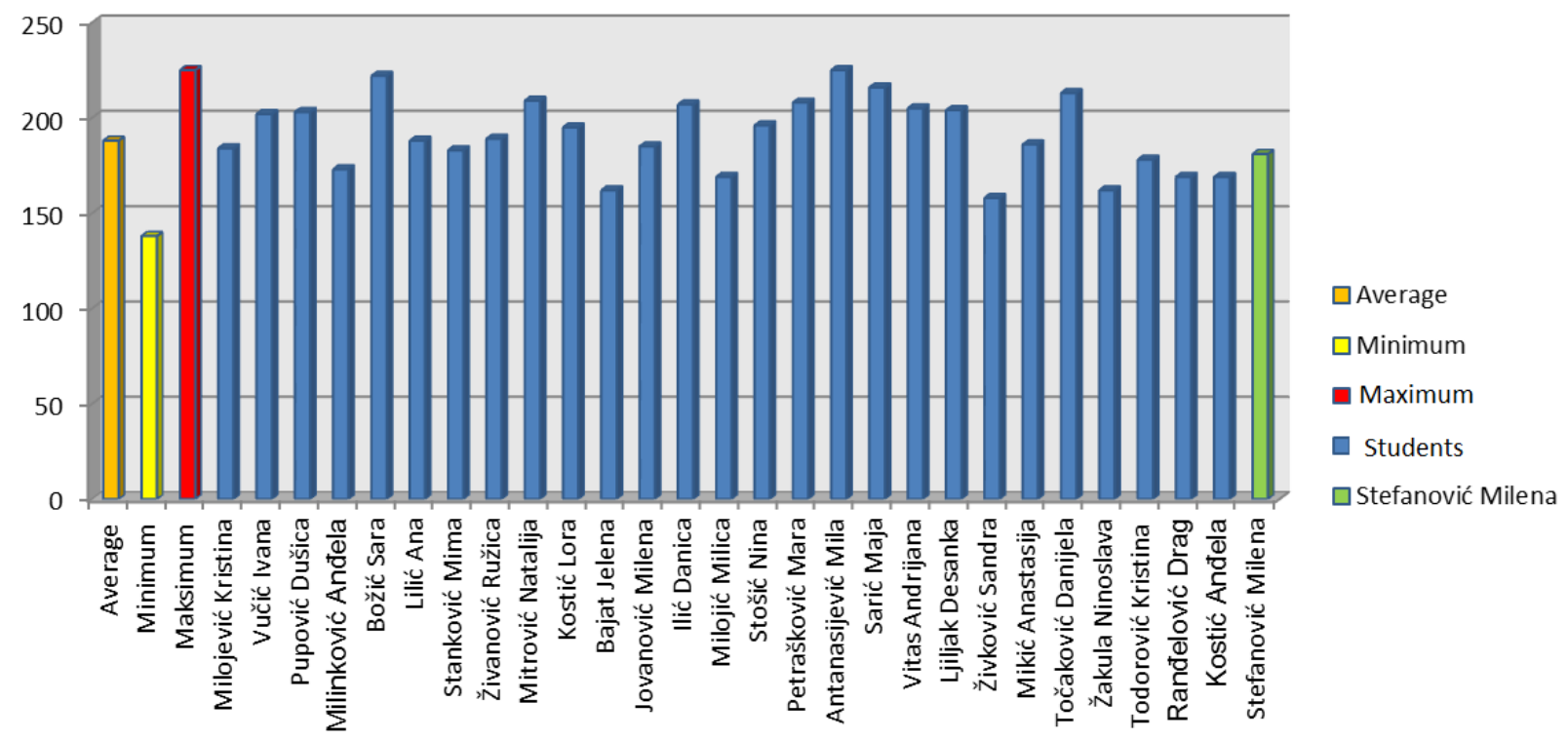

Figure 8. Standing Long Jump (SLJ) - Diagram of the PE Female students Total sample results.

\subsection{Case Study - Dominant-Hand-Grip (DHG)}

On the base of implemented testing procedure, using dynamometer for the evaluation of the isometric muscles potential of the dominant hand, results of the all PE female students are provided in form of two Figures (9-10), and on the Figure (9) 4 levels are presented, as was explained in the Legend-9 below. On the Figure (10) the Total-sample results of the all PE female students are presented, placed in six equidistant segments (fitness zones), which point on the fact, that the results dispersion is not very high. On the presented Figures (9-10), it is evident that Milena Stefanović's OWN score $(48 \mathrm{~kg})$ is placed in the zone between AVERAGE $(41.65 \mathrm{~kg})$, and MAX-value $(56 \mathrm{~kg})$ of the all other PE female students (average fitness zone).

\subsection{Case Study - Sit-Ups-Abdominals (ABD)}

This test estimate speed, or repetitive strength (freq.) of the abdominal muscles potential in limited time $(30 \mathrm{sec})$ evaluated by the special defined test protocol, in regard to the arms position (hands close connected behind the neck), with flexed knees $\left(90^{\circ}\right)$, and fixed foots. On the base of testing performed, the PE female students results are presented in form of two Figures (11-12), and on the Figure (11) 4-levels are presented, as explained in Legend below.

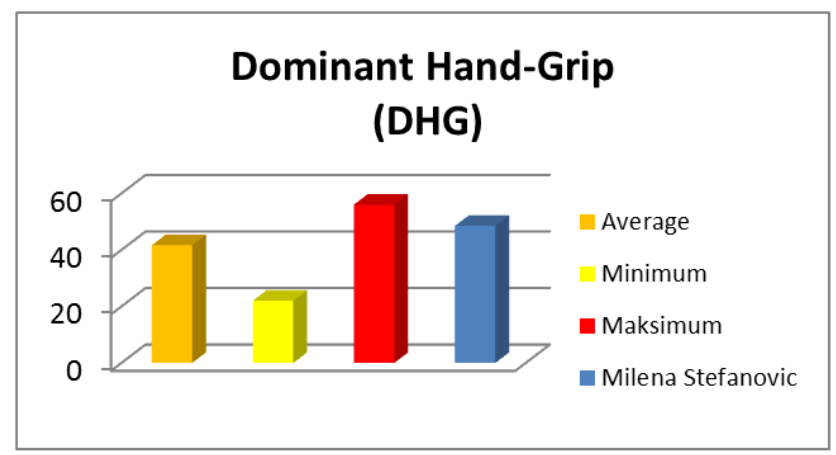

Figure 9. Dominant Hand-Grip (DHG) - AVERAGE-MIN-MAX-OWN.

Legend-9: AVERAGE (41.65kg), MIN (20kg), MAX (56kg), OWNStudent's score $(48.5 \mathrm{~kg})$

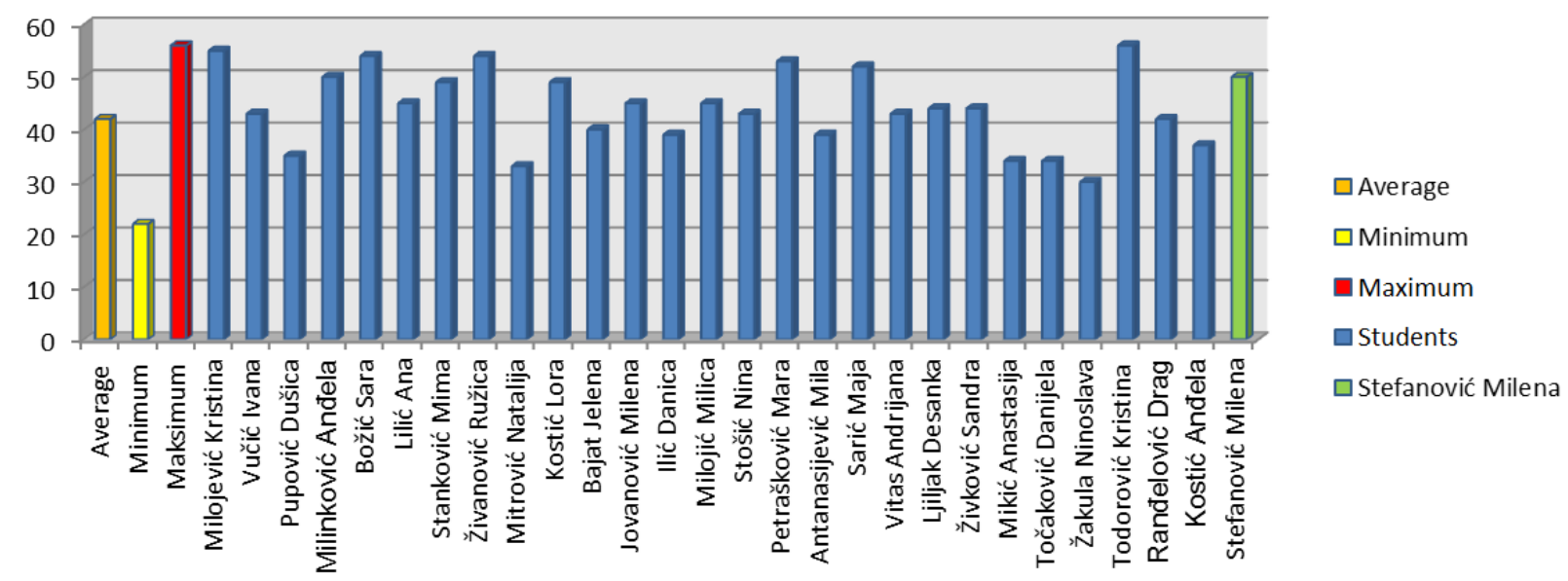

Figure 10. Dominant Hand-Grip Test (DHG) - Diagram of the PE Female students Total sample results. 
On the presented Figures (11-12) it is evident that the OWN Milena Stefanović's result (20 cyc/per $30 s)$ is placed in the zone between MIN-value (18 freq.), and AVERAGE-value (23.33 freq.) of the all other PE female students. Results are placed in seven equidistant segments, and her OWN score is in the below average fitness zone.

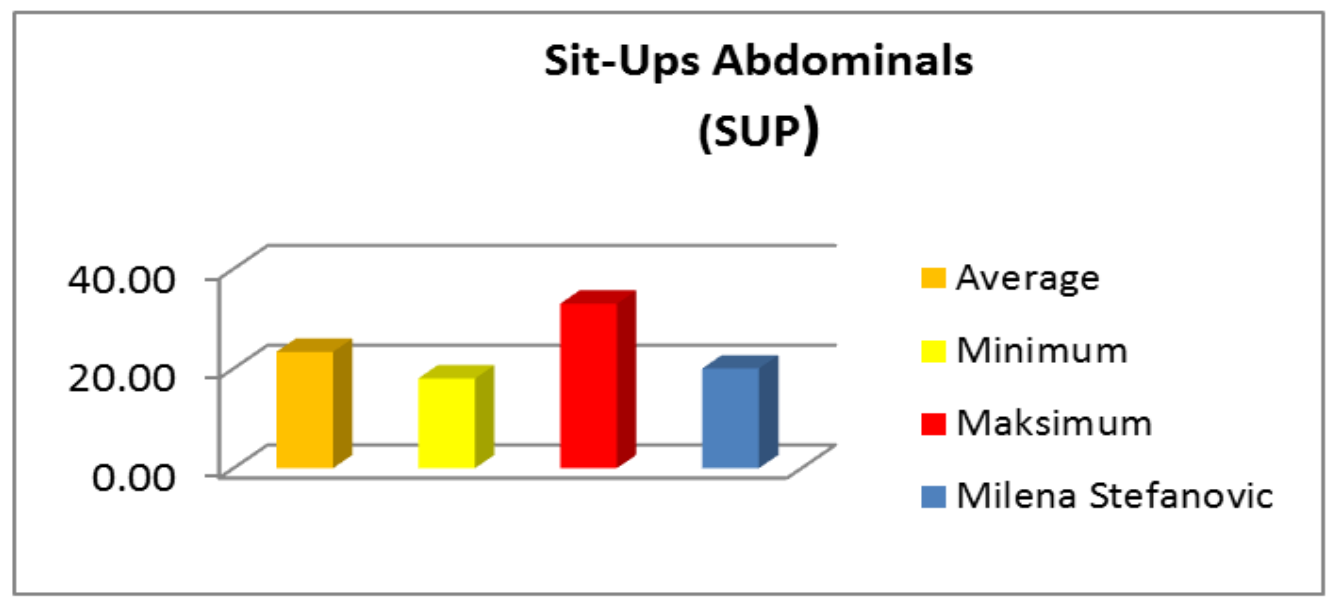

Legend-11: AVERAGE (23.6), MIN (18 freq.), MAX (33 freq.), OWN- student's score (20 freq.)

Figure 11. (SUP) - AVERAGE-MIN-MAX-OWN.

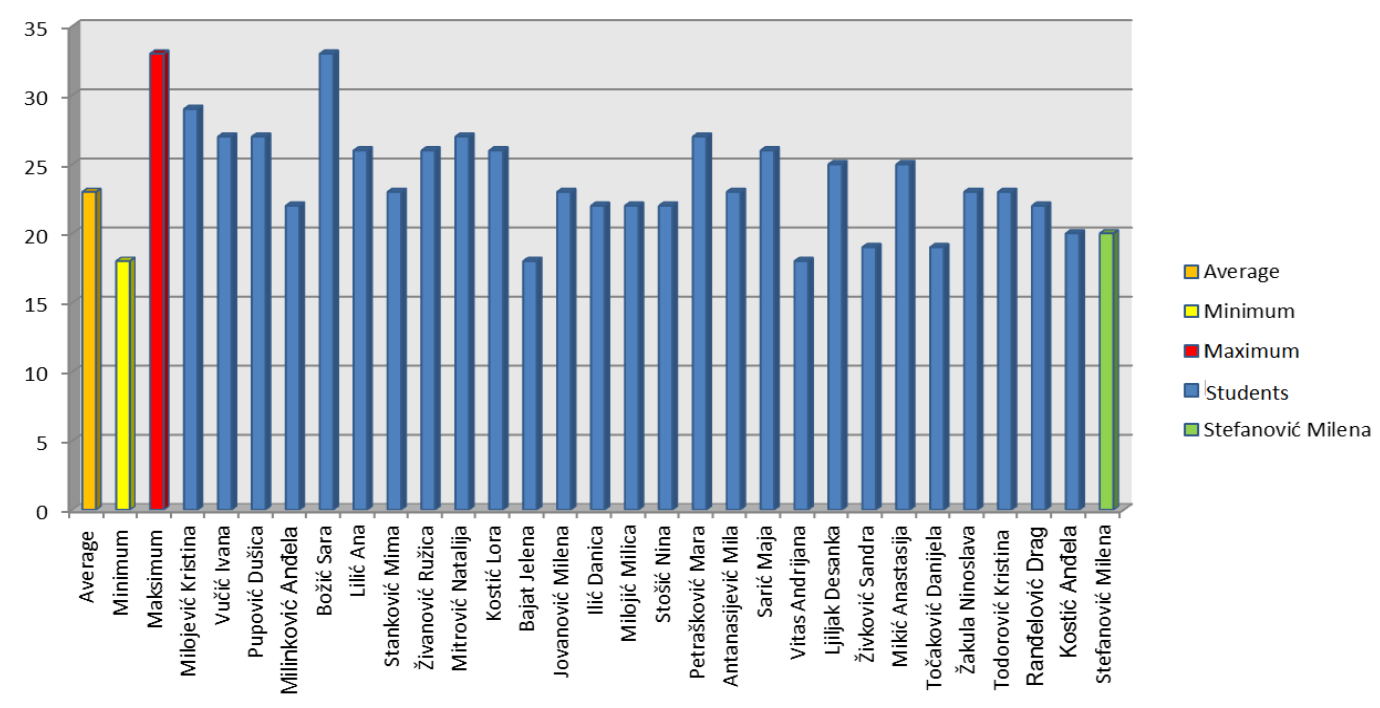

Figure 12. Sit-Ups-Abdominals (SUP) - Diagram of the PE Female students Total sample results.

\subsection{Case Study - Flexed Arms Hands-Grip Hang (FAH)}

The comparison of Milena Stefanović's individual score in relation to the basic descriptive parameters (MIN-MAX, and AVERAGE-value) of the all other PE female students, within the test for the estimation of so called Static endurance, which evaluates the isometric muscle strength of the upper body (arms and shoulders) is presented in Figure 13. Results are provided in $0.1 \mathrm{sec}$, as presented in Legend-13 below.

On the provided Figures: (13), and (15) it is evident that the Milena Stefanović's OWN score $(14.98 \mathrm{sec})$ is placed between MAX-value (46.85 sec), and AVERAGE-value $(11.73 \mathrm{sec})$, in view of the ten equidistant levels (above average fitness zones). On this test is noted very high result's dispersion.

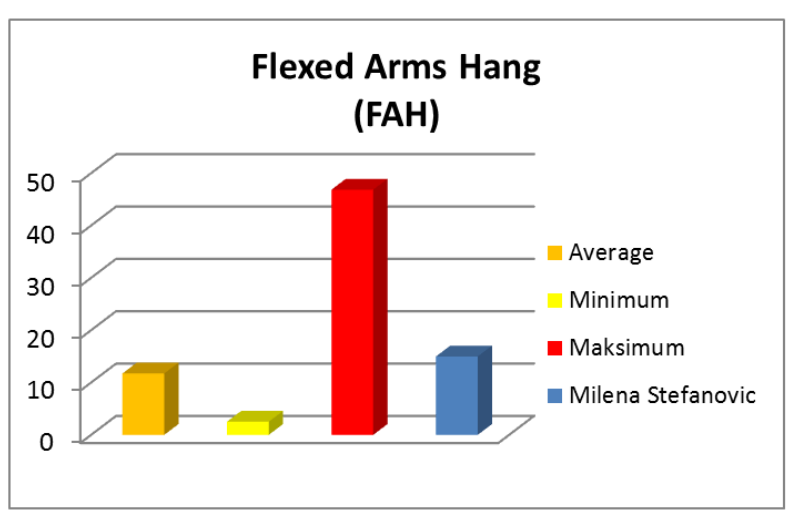

Figure 13. Flexed Arms Hang (FAH) AVERAGE-MIN-MAX-OWN

Legend-13: AVERAGE (12.98 s), MIN (2.51 s), MAX (46.85 s), OWNstudent's score (14.98 s) 


\subsection{Case Study-Agility Test* (10x5m)}

On the agility test $(10 \times 5 \mathrm{~m})$, which estimates running speed between cones it is necessary to possess the high level of the lower extremities explosive strength, as well as a good whole body move-ability, and speed. Comparison of the student's OWN score $(19.8 s)$, in relation to the basic descriptive parameters: MAX $(24.05 s)$, AVERAGE $(21.63 s)$, and MINvalue $(18.43 s)$ within the PE female students on the agility test $(10 \times 5 \mathrm{~m})$, and with the consideration of inverse value* (MIN-the best result, and opposite) point out that her score is placed in the below average zone.

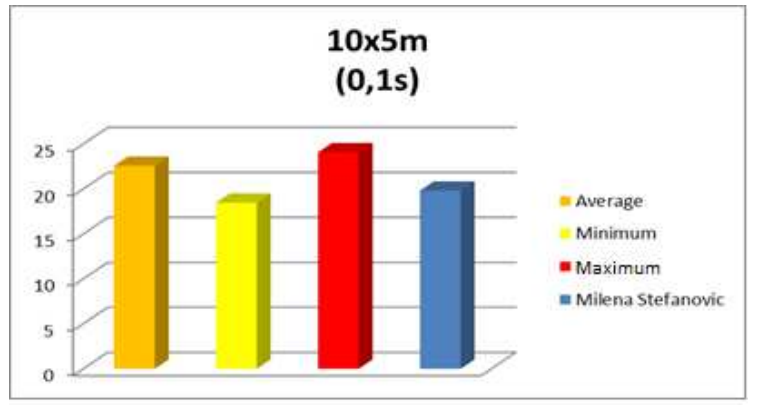

Figure 14. Agility $(10 \times 5 m) *-A V E R A G E-M I N-M A X-O W N$

Legend-15: AVERAGE (21.63s), MIN (18.43s), MAX (24.05s), OWNStudent's score (19.8 s). *Inverse value
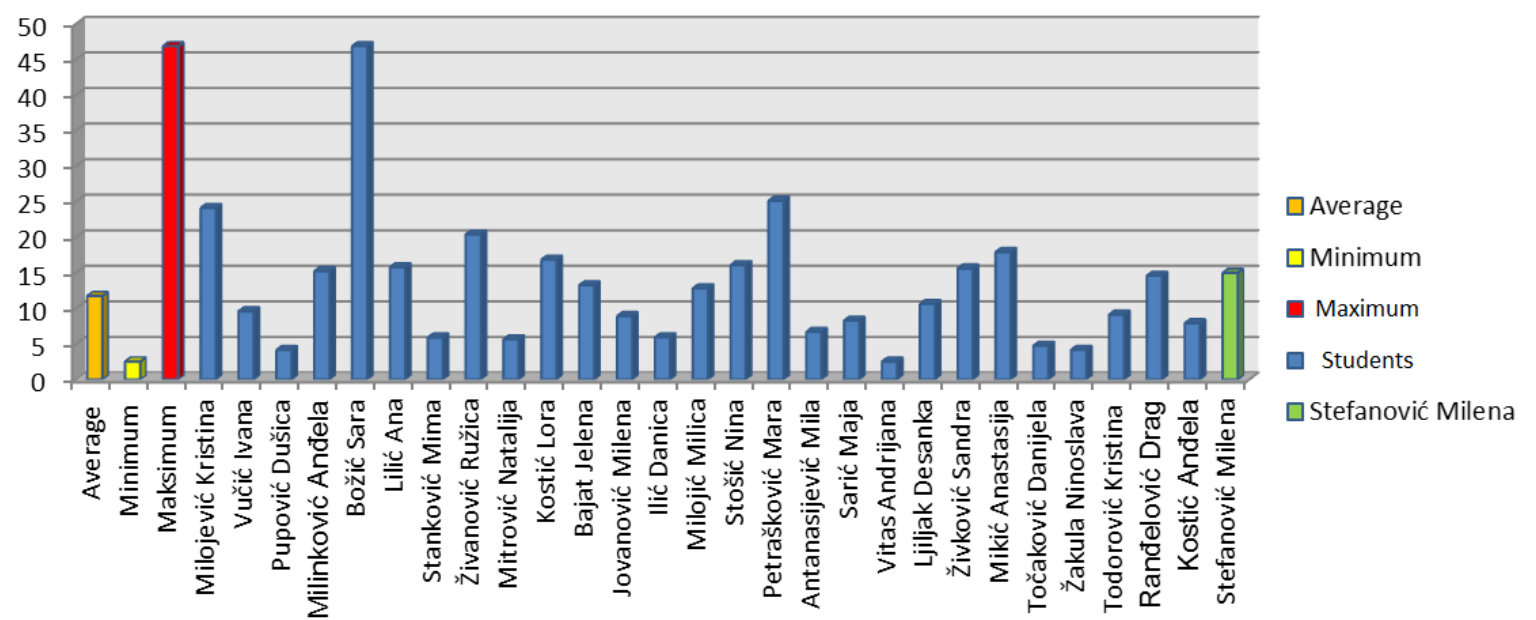

Figure 15. Flexed Arms Hang - Diagram of the PE Female students Total sample results.

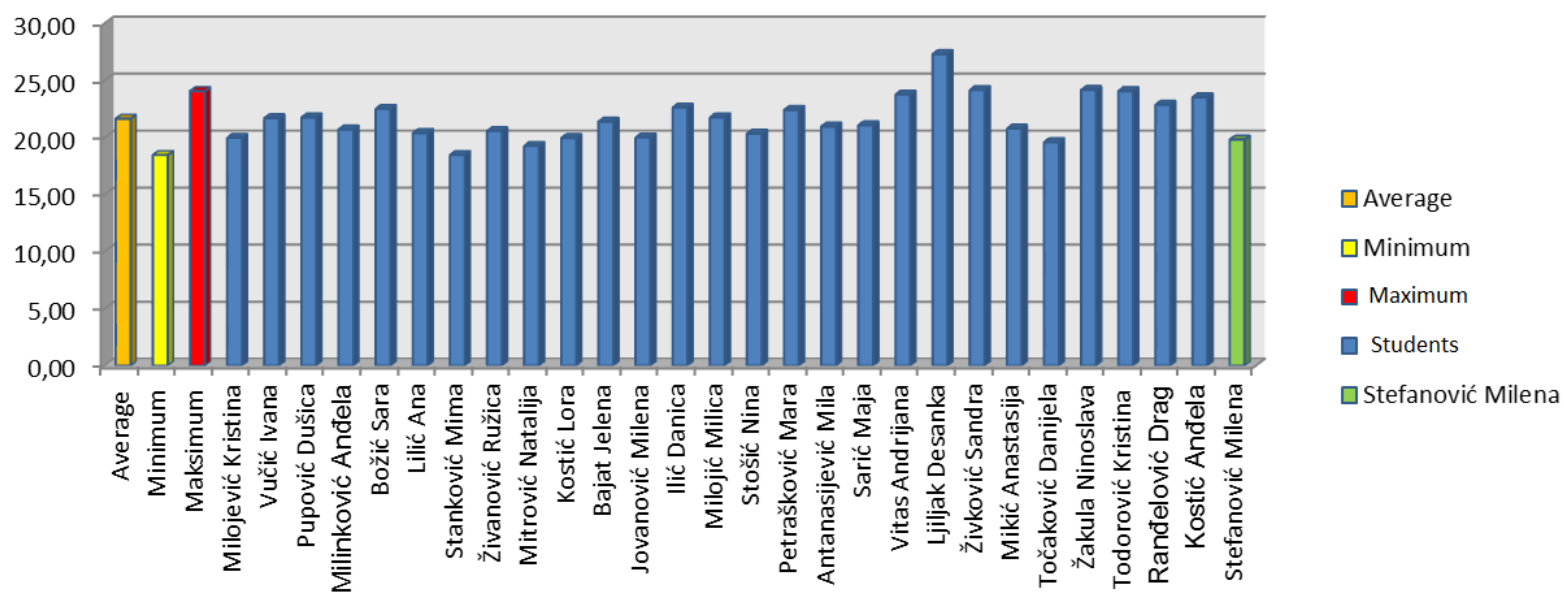

Figure 16. Shuttle-Run-Agility Test $(10 \times 5 \mathrm{~m})^{*}$-Diagram of the PE Female students Total sample results.

\subsection{Case Study-Cardio-Respiratory-Endurance-(CRE)}

According to test protocol, and realized testing procedure, and with the recalculation of the students' scores, using an adequate (Beep-test), procedure provided by [17] based on gender, chronological age, body high, and body weight parameters, and completed attempts of $20 \mathrm{~m}$ distance-ran, the estimated PE female students scores, provided in $(\mathrm{ml} / \mathrm{kg} / \mathrm{min})$ are presented in Figures (17-18). On the Figure (17) 4-levels are presented, as explained in Legend-17 below.

On the Figure (18) results of the all Physical Education female students are presented, placed in particular equidistant segments (nine fitness zones), because of the very high results dispersion. According to [16], when PE students were divided in three different endurance levels, applied data procession and results analysis do not establish any statistically significant differences.

On the provided figures (17-18) it is evident that Milena 
Stefanović's OWN score $(28.8 \mathrm{ml} / \mathrm{kg} / \mathrm{min})$ is placed between MIN (16.6 ml/kg/min), and AVERAGE (29.89 ml/kg/min), within the nine equidistant segments (average fitness zone), and Sara Božić's OWN-score is placed in the above average fitness zone. On this test very high results' dispersion is noted (Figure 18).

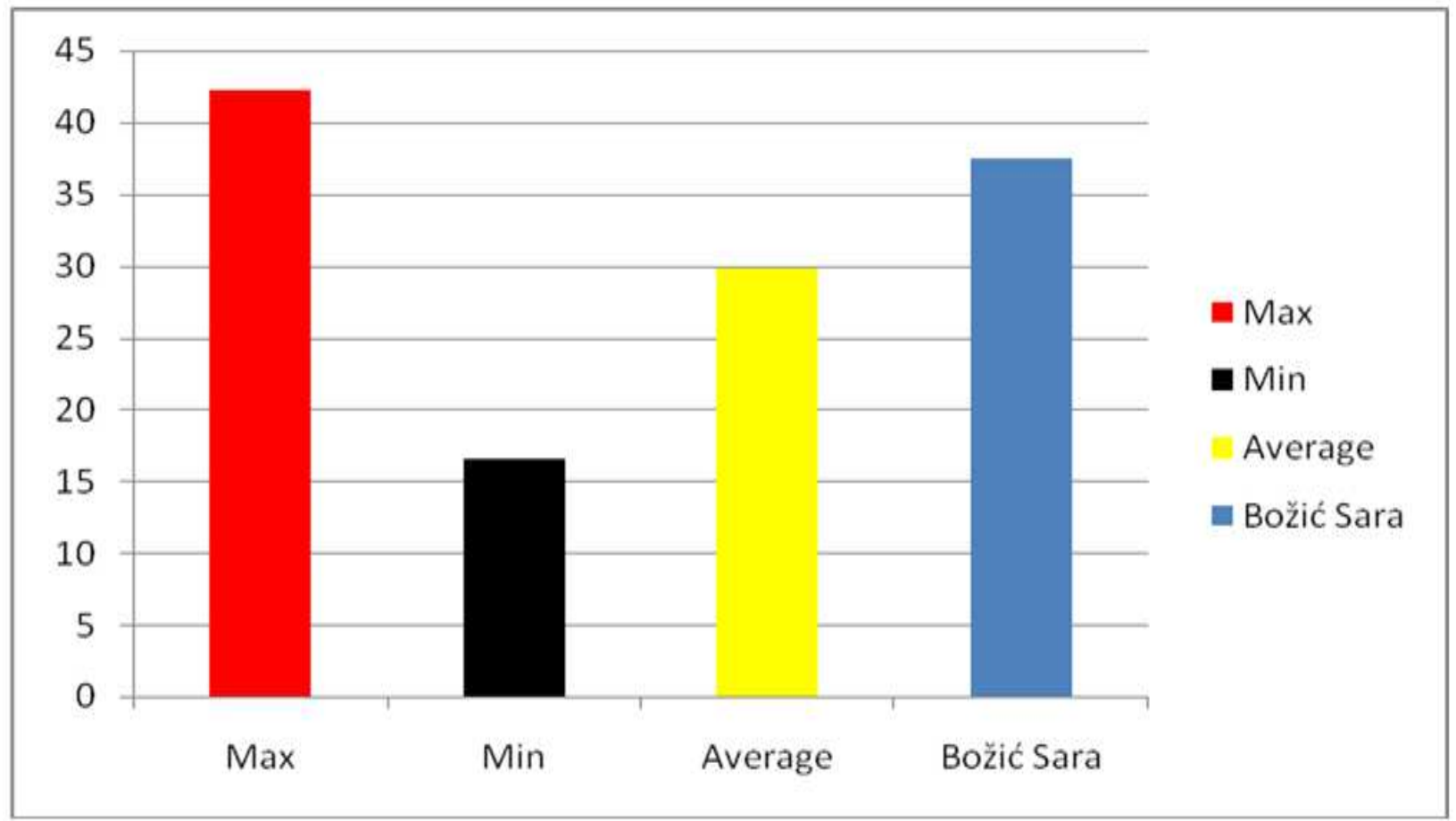

Legend-17: MAX (42.2ml/kg/min); MIN (16.6ml/kg/min); AVERAGE (29.893 ml/kg/min); OWN-Student's score (37.5 ml/kg/min).

Figure 17. Beep-test (CRE) - AVERAGE-MIN-MAX-OWN.

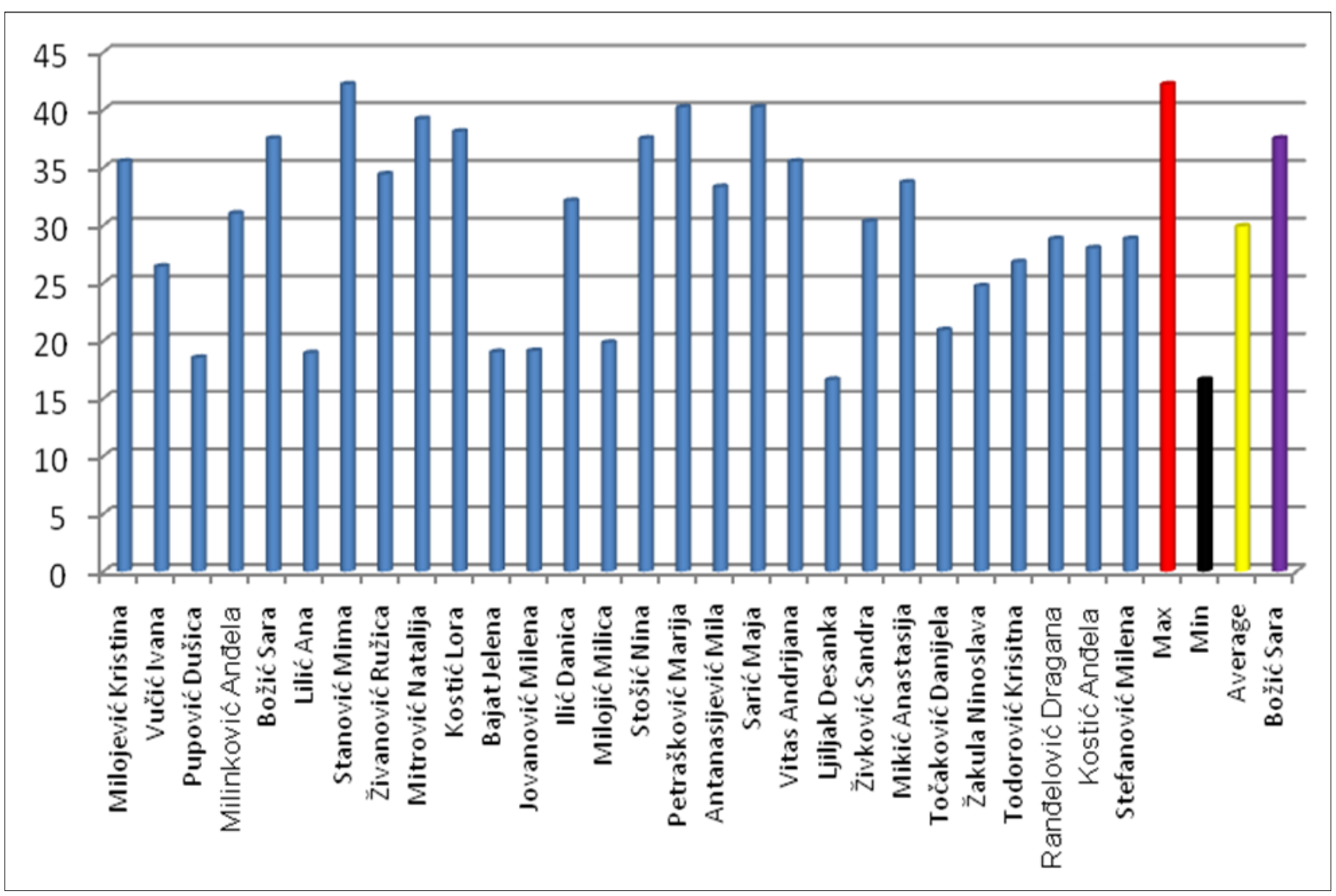

Figure 18. Beep-test-Cardio-Respiratory-Endurance (CRE) - Diagram of the PE Female students Total sample results. 


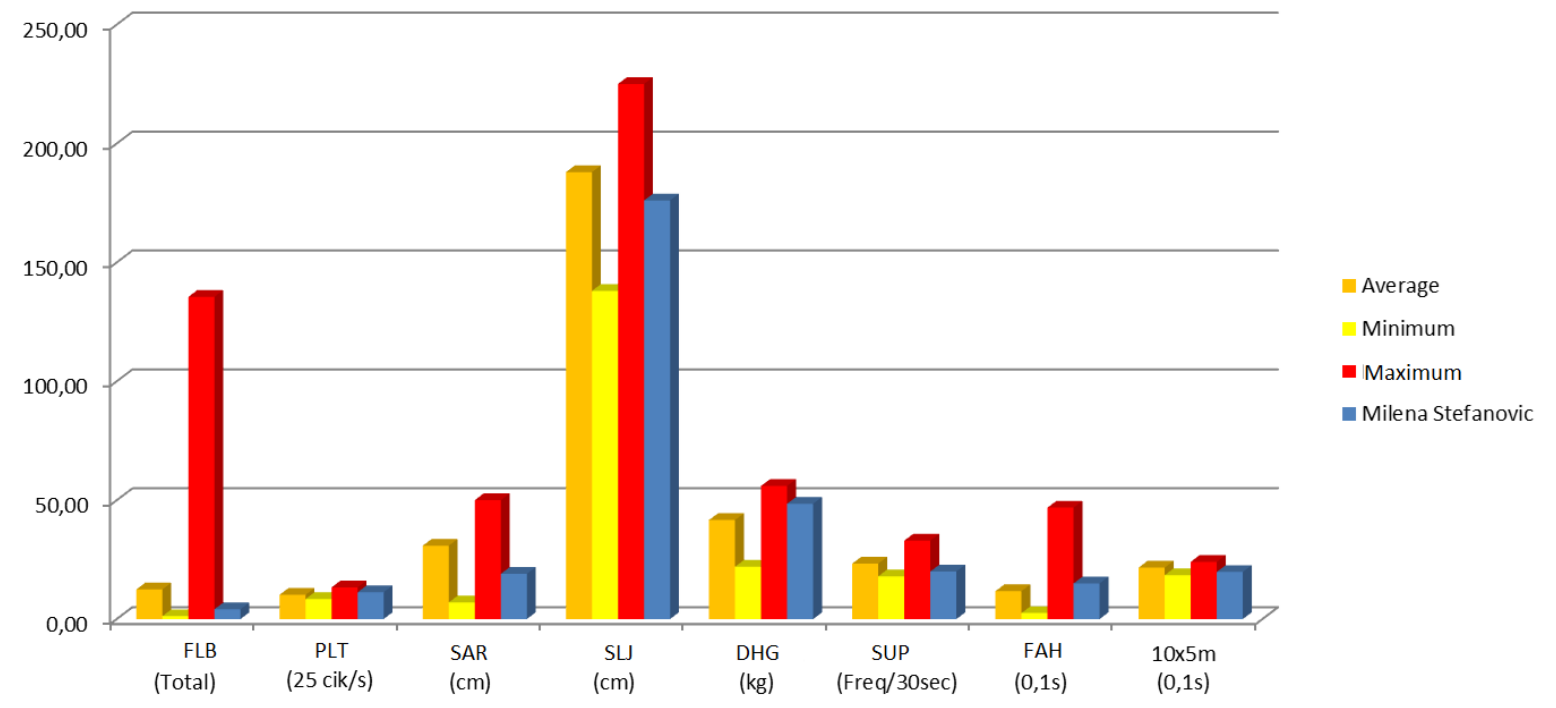

Figure 19. Overview of the EUROFIT-TEST items (1-8) results presented in 4-levels (AVERAGE-MIN-MAX-OWN) within five equidistant segments.

Legend-19: FLB-Flamingo-Balance-Test (Total Sum of 3-attempts), PLT-Plate-Tapping-Test (25cyc/s)*, SAR-Sit-and-Reach-Test (cm), SLJ-Standing-LongJump (cm), DHG-Dominant Hand-Grip (kg), SUP-Sit-Ups-Abdominals (Freq./30s), FAH-Flexed-Arms-Hang (0.1s), 10x5m-Agility- (0.1s)*.

\subsection{Final Considerations on "Eurofit-Test" Results}

As we can see in Figure (19) 4-levels results are presented (1-8 items of Eurofit-Test), placed in equal, five equidistant segments. The highest differences, relative to the estimated scores of PE female students (MAX-MIN, AVERAGEOWN) are in the first item FLB, Flamingo tests, for the balance ability estimation, and in FAH test, for the arms and shoulders isometric muscles potential estimation (Flexed Arms hand-grip Hang - Static Endurance).

On the Eurofit-Test item for the estimation of the movement frequency speed (Plate-Taping Test with dominant hand), shuttle run $(10 \times 5 \mathrm{~m})$ for the agility estimation, the results of PE female students are very balanced (unified), and placed in the same, first equidistant segment/fitness zone (inverse values)*.

That points out on the better scores of PE female students in these tests, which belong to the area of the speed movement frequency, and the whole body move ability (agility).

In contrary, Flamingo-Balance test has the weakest results, except MAX-value. All other scores are placed in the below average, or minimal fitness zone. In Table (1) those results are presented in regard of comparison to the student Milena Stefanović's OWN-score and the adequate fitness zone.

Table 1. PE female students Total sample (AVERAGE, MIN-MAX) results compared to OWN-M.S. score placed in adequate Fitness zone.

\begin{tabular}{llllll}
\hline Eurofit-Test & AVERAGE & MIN & MAX & M. S. & Fitness zone \\
\hline 1. FLB & 13.27 & 1.2 & 135.5 & 5.14 & below AV \\
2. PLT $(\mathrm{s})$ & $12.43^{*}$ & $8.43^{*}$ & $13.34^{*}$ & $11.24^{*}$ & above AV* \\
3. SAR $(\mathrm{cm})$ & 30.83 & 07 & 50 & 19 & below AV \\
4. SLJ $(\mathrm{cm})$ & 187.9 & 138 & 225 & 176 & below AV \\
5. DHG (kg) & 41.65 & 22 & 56 & 48.5 & above AV \\
6. SUP (freq./30s) & 23.33 & 18 & 33 & 20 & above AV \\
7. FAH (sec) & 11.37 & 2.51 & 46.85 & 14.98 & above AV \\
8. $10 \times 5 *(\mathrm{~s})$ & $24.05^{*}$ & $18.43^{*}$ & $21.63^{*}$ & $19.8^{*}$ & below AV* \\
9. CRE $(\mathrm{ml} / \mathrm{kg} / \mathrm{min})$ & 29.89 & 16.6 & 42.2 & 28.8 & Average \\
\hline
\end{tabular}

Legend (Table 1-2): 1. FLB-Flamingo-Balance-Test (s); 2. PLT-Plate-Tapping-Test (25 cycles/s*); 3. SAR-Sit and Reach (cm); 4. SLJ-Standing-Long-Jump $(0.5 \mathrm{~cm})$; 5. DHG-Dominant-Hand-Grip (kg); 6. SUP-Sit-Ups (freq. $/ 30 \mathrm{~s}) ; 7$. FAH-Flexed Arms Hang (s); 8. 10x5m-Agility (s*); 9. CRE- CardioRespiratory-Endurance - Beep Test $(\mathrm{ml} / \mathrm{kg} / \mathrm{min}) *$ inverse value (MIN- the best result, and opposite).

Table 2. Overview of the absolute (f), and relative (\%) Eurofit-Test numeric values distribution within some levels of Fitness zones.

\begin{tabular}{llllll}
\hline Eurofit-Test / Fitness Zone & MIN (1) Unsatisfied & B-AV. (2) Satisfied & AVERAGE (3) Good & A-AV. (4) Very good & MAX (5) Excellent \\
\hline $\mathbf{( N = 2 8 )}$ & $\mathbf{f ~ ( \% )}$ & $\mathbf{f}(\%)$ & f (\%) & f (\%) & f (\%) \\
\hline 1. FLB & $1(3.57)$ & $18(62.28)$ & $1(3.57)$ & $7(25.0)$ & $1(3.57)$ \\
2. PLT* (s) & $1(3.6)$ & $10(35.7)$ & $3(10.7)$ & $15(53.6)$ & $1(3.6)$ \\
3. SAR (cm) & $1(3.57)$ & $9(32.14)$ & $1(3.57)$ & $16(57.14)$ & $1(3.57)$ \\
4. SLJ (cm) & $1(3.57)$ & $17(60.71)$ & $1(3.57)$ & $8(28.57)$ & $1(3.57)$ \\
\hline
\end{tabular}




\begin{tabular}{llllll}
\hline Eurofit-Test / Fitness Zone & MIN (1) Unsatisfied & B-AV. (2) Satisfied & AVERAGE (3) Good & A-AV. (4) Very good & MAX (5) Excellent \\
\hline $\mathbf{( N = 2 8 )}$ & f (\%) & f (\%) & f (\%) & f (\%) & f (\%) \\
\hline 5. DHG (kg) & $1(3.57)$ & $8(28.57)$ & $1(3.57)$ & $17(60.71)$ & $1(3.57)$ \\
6. SUP (freq./30s) & $1(3.57)$ & $10(35.71)$ & $1(3.57)$ & $15(53.57)$ & $1(3.57)$ \\
7. FAH (sec) & $1(3.57)$ & $11(39.28)$ & $1(3.57)$ & $14(50.0)$ & $1(3.57)$ \\
8. $10 \times 5 *(\mathrm{~s})$ & $1(3.6)$ & $11(39.3)$ & $1(3.6)$ & $14(50)$ & $1(3.6)$ \\
9. CRE $(\mathrm{ml} / \mathrm{kg} / \mathrm{min})$ & $4(14.28)$ & $6(21.43)$ & $7(25.0)$ & $10(35.71)$ & $1(3.57)$ \\
\hline
\end{tabular}

In Table 2 absolute (f) and relative (\%) frequencies are provided, of the nine (9) Eurofit-Test items, within five levels of Fitness zones, considered as unsatisfied (1) to excellent (5).

In the balance test (FLB) the majority of results $(62.28 \%)$ are placed in the below average fitness zone. In the plate-tapping test/ speed of movement frequency test (PLT), the majority of results (53.57\%), are placed in the above average (A-AV.) fitness zone, with consideration of inverse values* of results.

Table 3. Comparative indices of the Average values of provided variables for the evaluation of Body Composition and EUROFIT-Test items.

\begin{tabular}{|c|c|c|c|c|c|c|}
\hline Variables & Initial (I-1) & & Final ( & & $1987 / 1988$ & $2015 / 2016$ \\
\hline Body-Com/ Eurofit-Test & PF-PU & SVK & PFPU & SVK & U-Lj-SLO & FSPE-UN-SRB \\
\hline B-H (cm) & 166.13 & 168.51 & 166.51 & 168.20 & 178.0 & 167.85 \\
\hline B-W (kg) & 57.39 & 55.21 & 55.55 & 56.69 & 76.0 & 60.255 \\
\hline BMI & 20.3 & - & 19.51 & - & - & 21.385 \\
\hline 1. FLB $(s)$ & 4.14 & 12.59 & 2.44 & 11.59 & & 13.26 \\
\hline 2. $\operatorname{PLT}(s)^{*}$ & & & & & & $12.43 *$ \\
\hline 4. SLJ (cm) & 166.12 & 173.61 & 178.57 & 173.77 & 216 & 189 \\
\hline 5. DHG (kg) & & & & & & 41.65 \\
\hline 6. SUP (freq./30s) & 21.02 & 23.51 & 23.57 & 25.10 & - & 23.33 \\
\hline 7. FAH $(s)$ & 27.56 & 22.71 & 35.51 & 22.14 & 69.0 & 11.37 \\
\hline 8. $10 \times 5(s)^{*}$ & 22.36 & 21.07 & 21.28 & 21.78 & - & $22.55^{*}$ \\
\hline 9. $\mathrm{CRE}(\mathrm{ml} / \mathrm{kg} / \mathrm{min})$ & 37.79 & 37.71 & 41.61 & 35.71 & - & 29.89 \\
\hline
\end{tabular}

Legend: (PF-PU) - female students of Pedagogical Faculty, University of Prešov, (SVK) - General population in Slovakia, (I-1) - Initial, and (F-2) - Final measurement, (U-Lj-SLO) - female students of University of Ljubljana in F YR of Slovenia, (FSPE-UN-SRB) - current sample of PE female students, University of Niš in Serbia, * inverse value (MIN - the best result, and opposite), ${ }^{* *}$ due to testing protocol differences, the real score is $25 \mathrm{~cm}$.

Test results for the estimation of the lower extremities flexibility - sit and reach (SAR), are placed in the above average (A-AV.) fitness zone (57.14\%).

Results in test item for the estimation of lower extremities explosive strength (SLJ), are placed in below average (BAV.) fitness zone $(60.71 \%)$.

In the test item for the dominant hand isometric muscles strengths estimation (DHG), the majority of results $(60.7 \%)$ are placed in the above average (A-AV.) fitness zone, as well as in items for the estimation of the repetitive strength of abdominal muscles (SUP) with 53.57\%, than static endurance (FAH) of arms and shoulders (50\%), agility (10x5) with $50 \%$, and cardio respiratory endurance (CRE) with $(35.7 \%)$.

\section{Discussion}

\subsection{Physical Fitness of Children, Youth and Young Adults}

In many countries of the world, experts are also focused on solving issues of population health state, its promotion and the searching for factors closely related to this problem. Statistical data continuously indicate the unsatisfactory state of health of the population, both in our country and in the (EU), and other European and the world countries. Our citizens belong to those European countries with the shortest average (mean) value of the length-life.

At this point we are faced with a difficult task - especially to fight the passivity of a large part of our population, with reduced responsibility for their own health and physical fitness. The results of modern research proves, even with higher reliability, that appropriate physical activities have a positive impact on health improvement, physical fitness and motor efficiency, both in school and student population, as well as in adult population. National programs for health promotion, in some countries, also contain Development Programs and improvement of motor skills, which should eventually contribute to the general improvement in the health status of the population in these countries. Health in childhood and adolescence is considered optimal periods to create of positive habits and lasting relationship with regular sports and physical activities during future life. One cannot imagine the planning and implementation of programs in motor activity without control of their efficiency, with respect of the individual differences and potential possibilities for development of certain motor skills. For that reason the fitness tests are considered as the most important means of pedagogical control, first of all in certain sensitive periods of the human development. So, the constructing of the test-batteries is considered as the starting point, both in 
our country and the world-wide, and the goal to be achieved. Due to the different approaches to the solution of the health problems of the population, coupled with the physical fitness of children and youth of school age, and young adults, as well as the lack of unified testing methods of physical fitness, so far has been impossible in correct and methodologically appropriate way to compare the results of previous, and contemporary researches. The international organization dealing with the issue of testing, as well as experts in physical education in our country for many years have to initiate the establishment of a single system, which will allow you to determine the level of basic motor skills, as in children and youth, as well as in young adult population [8].

\subsection{Contribution to the Unified Testing Methods Evaluation of Physical Fitness}

National programs for health promotion, in some countries, also contain Development Programs and improvement of motor skills, which should eventually contribute to the general improvement in the health status of the population in these countries. Health in childhood and adolescence is considered optimal periods to create of positive habits and lasting relationship with regular sports and physical activities during future life.

However, until now, has not found universal test-battery, accepted in practice of physical education, which could be internationally applicable, for comparison of results in this area. Experts in the field of PE, and Sport in some EU countries (Slovakia, Czech Republic, Poland, Slovenia, Bulgaria, Finland, Germany, Belgium, and Netherlands) by [4], [8], [10], [11], as well as in our home country (Serbia), still insist to use the traditional battery of tests, or with various modifications [9].

Table 4. The General Scale of Points for Results Evaluation within nine (9) Fitness Zones.

\begin{tabular}{lllll}
\hline Eurofit-Test /Points & EBA-MIN (1) & EBA-MIN (2) & BA (3) & BA (4) \\
\hline (1) FLB & $>5.5$ & $9-6$ & $10-19.9$ & $20-21.9$ \\
(2) PLT* & $>12.1$ & $12.1-11.1$ & $11.0-12.0$ & $10.9-10.5$ \\
(3) SAR & $<18.1$ & $18.1-21.1$ & $21.2-24$ & $24.1-27$ \\
(4) SLJ & $<149$ & $149.5-158$ & $158.5-166$ & $166.5-175$ \\
(5) DHG & $>20$ & $21-25$ & $26-30$ & $31-35$ \\
(6) SUP & $<15$ & $16-18$ & $19-21$ & $22-24$ \\
(7) FAH & $<9.4$ & $9.4-16.7$ & $16.8-24.2$ & $24.3-31.6$ \\
(8) $10 \times 5^{*}$ & $>24$ & $23.1-23.9$ & $22.4-23.8$ & $21.7-22.32$ \\
(9) CRE & $<16.6$ & $16.6-22.6$ & $22.7-27.7$ & $27.8-33.8$ \\
Fitness Zones & (1) Unsatisfied & (1.5) Unsatisfied & (2) Satisfied & $(2.5)$ Satisfied \\
\hline
\end{tabular}

Table 4. Continued.

\begin{tabular}{llllll}
\hline Eurofit-Test & AVR (5) & AA (6) & AA (7) & EAA-MAX (8) & EAA-MAX (9) \\
\hline (1) FLB & $22-24.9$ & $25-30$ & $31-45$ & $46-59$ & $<60$ \\
(2) PLT* & $10.4-10$ & $9.9-9.7$ & $9.6-9.8$ & $9.5-9.3$ & $<9.2$ \\
(3) SAR & $27.1-30$ & $30.1-32.9$ & $33-35.8$ & $35.9-38.8$ & $>38.8$ \\
(4) SLJ & $175.5-183$ & $184-190$ & $191-199$ & $200-207$ & $>207$ \\
(5) DHG & $36-40$ & $41-45$ & $45-50$ & $51-59$ & $<60$ \\
(6) SUP & $25-26$ & $27-28$ & $29-30$ & $31-32$ & $>33$ \\
(7) FAH & $31.7-39.2$ & $39.3-46.6$ & $46.7-54.1$ & $54.2-61.5$ & $>61.5$ \\
(8) $10 \times 5 *$ & $20.9-21.6$ & $20.1-20.8$ & $19.4-20.2$ & $18.6-19.3$ & $<18.6$ \\
(9) CRE & $33.9-39.9$ & $40.0-44.5$ & $44.6-50.0$ & $50.1-55.0$ & $>55.0$ \\
Fitness Zones & (3) Good & $(3.5)$ Very good & (4) Very good & $(4.5)$ Excellent & $(5)$ Excellent \\
\hline
\end{tabular}

Legend-4 Continued: (1) FLB - Flamingo (sec); (2) PLT - Plate-Tapping (25 cycles/sec*); (3) SAR - Sit and Reach (cm); (4) SLJ - Standing-Long-Jump (0.5 cm); (5) DHG - Dominant-Hand-Grip (kg); (6) SUP - Sit-Ups (freq./30 sec); (7) FAH - Flexed Arms Hang (sec); (8) 10x5m - Agility (sec*); (9) CRE Cardio-Respiratory- Endurance (ml/kg/min); EBA-MIN (1) - Extremely below average; EBA-MIN (1.5) - Extremely below average; BA (2) Below Average; BA (2.5) Below Average; AVR-Average (3); AA - Above Average (3.5); AA - Above Average (4); Extremely AA-MAX (4.5); Extremely AA-MAX (5)

Table 5. Evaluation of the PE female student's test results with the MAX-scores within some Eurofit-Test variables.

\begin{tabular}{|c|c|c|c|c|c|c|c|}
\hline Variables & Index 6902 & Index 6900 & Index 7035 & Index 7090 & Index 7034 & Index 6903 & Index 5245 \\
\hline E-T S (P) & $\mathrm{S}(\mathrm{P})$ & $\mathrm{S}(\mathrm{P})$ & $\mathrm{S}(\mathrm{P})$ & $\mathrm{S}(\mathrm{P})$ & $\mathrm{S}(\mathrm{P})$ & $\mathrm{S}(\mathrm{P})$ & $\mathrm{S}(\mathrm{P})$ \\
\hline (1) FLB & $135.5(9)$ & $36.4(7)$ & $21.7(4)$ & $8.66(2)$ & $28.6(6)$ & $27.05(6)$ & $5.1(1)$ \\
\hline (2) PLT* & $10.38(5)$ & $8.43(9)$ & $10.56(4)$ & $9.04(9)$ & $10.01(5)$ & $9.38(8)$ & $11.24(3)$ \\
\hline (3) SAR & $36(8)$ & $40(9)$ & $50(9)$ & $35(7)$ & $42(9)$ & $11(1)$ & $20(2)$ \\
\hline (4) SLJ & $188(6)$ & $222(9)$ & $216(9)$ & $194.5(7)$ & $234.5(9)$ & $202.5(8)$ & $181(5)$ \\
\hline (5) $\mathrm{DHG}$ & $45(6)$ & $54(8)$ & $52(8)$ & $56(8)$ & $39(5)$ & $49(7)$ & $50(7)$ \\
\hline (6) SUP & $26(3)$ & $33(9)$ & $26(3)$ & $23(2)$ & $23(2)$ & $23(2)$ & $20(1)$ \\
\hline (8) $10 \times 5 *$ & $20.38(6)$ & $19(8)$ & $21.06(5)$ & $24.05(1)$ & $20.95(5)$ & $18.45(9)$ & $19.8(7)$ \\
\hline (9) CRE & $18.9(2)$ & $37.5(3)$ & $40.2(6)$ & $26.8(2)$ & $33.3(4)$ & $42.2(6)$ & $28.8(4)$ \\
\hline Total Points & $47(58 \%)$ & $69(85.2 \%)$ & $49(60.5 \%)$ & $39(48 \%)$ & $46(56.8 \%)$ & $48(59.3 \%)$ & $32(39.5 \%)$ \\
\hline
\end{tabular}

Legend: Index - Student's ID Number; ET- Eurofit-Test, S (P) - Student's Score (Points achieved) 
In Table 3 are provided numerical data on conducted researches in some of these countries in regard to results comparison with the current study, heir considered.

Table 4 and continued... provides the Scale of Points for the Results Distribution, and Evaluation within nine Fitness Zones, considered as extremely below average-MIN (1) to extremely above average-MAX (9). This scale is constructed with respect of previous researches on this topic, and represents the mixture of various scales, suggested by [3], [6], [7], [8], [12], [15], [16], and [17].

Table 5 provides the evaluation of the most performance effective PE female student's, with MAX-scores within some Eurofit-Test items, recalculated by using an appropriate 9-level Scale of Points. The best score (69 Points) is achieved by Combat sport (Sambo) Athlete (6900), the second best score (49 Points) is achieved by Volleyball athlete (7035), and the third best score (48 Points) is achieved by Football athlete (6903), followed by (6902), Football athlete (47 Points), then Volleyball athlete (7034), with achieved (46 Points), and the Combat sportKarate Athlete (7090), who is achieved (39 Points), and the less performance effective was our Case study student (5245), as the oldest, and she scored 32 Points.

Table 6. Total Score of Points for the nine Eurofit-Test Items.

\begin{tabular}{lll}
\hline Fitness Level & Motor Efficiency & Student's ID \\
\hline (1) Insufficient & $<27$ & \\
(2) Very weak & $27-31$ & \\
(3) Weak & $32-36$ & 5245 \\
(4) Below average & $36-40$ & 7090 \\
(5) Average & $41-46$ & 7035 \\
(6) Above average & $47-51$ & $7035 / 6903 / 6902$ \\
(7) Very good & $52-56$ & \\
(8) Excellent & $57-61$ & \\
(9) Extraordinary & $>61$ & 6900 \\
\hline
\end{tabular}

We must stress the fact that this overview is not allinclusive, while the achieved Points of all other PE students were not presented here, but the Table-4 (Cont.) provides the opportunity for everyone to recalculate estimated scores, according to provided 9-levels Scale of Points.

Table 7. Confidence Interval (Points Difference Evaluation.

\begin{tabular}{lll}
\hline Points Difference & Evaluation & Student's ID \\
\hline $0-1$ & Very balanced & \\
$2-3$ & Balanced & \\
$4-5$ & Small dispersion & \\
$6-7$ & Moderate dispersion & $6900 ; 6902 ; 5245$ \\
8 & Very high dispersion & $7035 ; 6903 ; 7035 ; 7090$ \\
\hline
\end{tabular}

\subsection{Promoting of the Health-Related Physical Activity for Children, Youth and Young Adults}

The challenge for helping others to enjoy a healthy and active life is to move the focus of instruction from physical fitness toward physical activity. A consistent and repeated challenge for physical education programs is to teach how to maintain an active life style that promotes health and vitality [3].
Government administrators and all levels of educational institutions (school boards) often feel physical education as a subject to be considered only after all other subjects have received adequate coverage and support. Educational institutions teach children and youth haw to achieve academically in order to live a productive life. However, there is no higher priority in life than health.

Provided previous, and contemporary studies have documented many health benefits derived from moderate and regular physical activity. The major conclusions were that people of all ages, both male and female, may have additional health benefits that are gained through greater amounts or intensities of physical activity.

Never before has a body of research been compiled to show the strong need for physical activity in the lives of youth. Activity programs and physical education today has a clearer mandate than ever to play an important role in the total school curriculum. The fitness and activity programs must produce an enjoyable and positive social experience so children develop a positive attitude toward activity [12].

A commonly held point of view among physical education teachers is that children today are less fit than children were in the past. This opinion is used as a justification for more physical education time in schools. One of the many reasons that people continue to believe that children and youth are unfit is that definition of fitness have constantly changed. Never fitness tests are focusing on health-related fitness and its relationship to good health and feelings of well-being. High performance on fitness tests items is not necessary for good health. Health-related fitness standards reveal that the majority of children and school youth are fit. A significant amount of fitness test performance is explained by heredity [2].

Various other factors such as environment, nutrition and maturation affect fitness performance as reflected in fitness test scores.

Beyond heredity lies another factor that predisposes some youngsters to high (or low) performance, such is "trainability", which has strong genetic limitations. Trainability means that some individuals receive more benefits from training (regular physical activity) than do others.

Another factor that impacts fitness performance is physical maturation. If two individuals are the same age and sex, but one is physiologically older (advanced skeletal maturation), the more mature individual usually performs better on tests than does the less mature.

Because age does not accurately reflect physical maturity, an immature active individual might score lower than a more mature, less active individual even though they are the same ages, which also play a role in fitness performance. For years, schools have focused on training students and raising their fitness levels. Promoting and encouraging physical activity is an outcome that can be accomplished by all individuals, regardless of ability or personal interests. Regular activity for children increases the probability of an active adult lifestyle. 
Finally, physical activity benefits those individuals who need it the most - the unskilled and obese individuals. These have often find it difficult to play in a sport setting that demands coordination speed and quickness. However, they can be successful in a walking, swimming, or biking program that promotes a level of participation that can be maintained throughout the lifespan. [12]

\section{Conclusions}

The results of this pilot study have provided us with the answers to the questions, as defined in the introductory part of the study, but the most important issue was dealing with kind of somatic and motor precondition that should meet the PE student with respect to universality and specificity of studies, in the time of the enrollment in the high education institution.

Because of the relatively small sample-size of examinees ( $\mathrm{N}=28$, PE female students) on which was implemented testing of the physical fitness, by applying Eurofit-Test, the results of this study are not possible to be generalized.

This study provides some data on physical fitness level of PE female students and contributes to the updating and expansion of empirical and scientific information on the state of some physical abilities and physical fitness.

Provided Scales, for the Eurofit-Test results, and PE female students evaluation, point out on the average performance efficiency, up $39.5(\%)$ to $85.2(\%)$ within selected students. At the same time, the study may contribute to this profile of individuals, by establishing norms (standards) for the evaluation of general movement capabilities.

Current research has been realized as a part of the students study research task, in framework of the doctoral academic studies (DAS), and the mandatory teaching practice within the basic academic studies (BAS), and Rhythmic gymnastics, as individual sport specific professional subject, intended for the female students only. Testing was conducted at the end of the 3rd study year (summer semester), in 2015-2016 school year, with applying of the adequate scientific methodology, in regard to avoid some irregularities, whether for objective or subjective reasons.

At the same time, this study has also the practical contribution, while it might have an impact on the better objectivity in all other future studies, with a similar orientation, when someone has to compare the own results with actual data from this study.

\section{Practical Applications}

The Basic motor abilities status diagnosis and Physical Fitness evaluation can provide valuable insights into the different capacities of athletes and PE students. A detailed profile allows determination of the underlying performance limitations rather than simply testing a narrow range of qualities.

This allows the PE educators, fitness instructors and conditioning practitioner to individualize sport training programs, or PE classes content. The basic motor abilities and fitness tests chosen should be reliable and valid and take into account the requirements of the sport and what is a meaningful change in performance.

The results of these tests need to be reported in a clear, meaningful, and timely manner for coaches, fitness instructors and PE teachers if they are to have maximal impact on training programs. Finally, the practitioner can use this evidence-based information in conjunction with the art of coaching to maximize training program effectiveness.

\section{References}

[1] Adam, C., Klissouras, V., Ravazzolo, M., et al. (1988). EUROFIT: European test of physical fitness. Rome: Council of Europe, Committee for the development of sport, CDSS.

[2] Bouchard, C. (1990). Discussion: Heredity, fitness and health. In C. Bouchard, R. J. Shepard, T. Stephens, J. R. Sutton, \& B. D. McPherson (Eds.), Exercise, Fitness and Health. Human Kinetics, Champaign. IL, pp. 147-153.

[3] Bouchard, C. E., Shepard, R. J., \& Stephens, T. E. (1994). Physical activity, fitness, and health: International proceedings and consensus statement. International Consensus Symposium on Physical Activity, Fitness, and Health, 2nd, May, 1992, Toronto, ON, Canada.

[4] Burnik, S., Stanič, J., Makuc, V. (1991). The development and evaluation of some movement activities of the Ljubljana University students (in Slovene): "Ugotavljanje in preverjanje nekaterih gibalnih sposobnosti študentov ljubljanske univerze". ŠPORT revija za teoretična in praktična vprašanja športa, letnik XXXIX, številka 1 (1991): 36-38. YU ISSN 0353-7455.

[5] Council of Europe (1983). Testing physical fitness EUROFIT experimental battery: provisional handbook. Strasbourg: The Council.

[6] Council of Europe (1987). Recommendation no. r (87) 9 of the Committee of ministers to member states on the EUROFIT tests of physical fitness. Retrieved-Web http://www.coe.int/t/dg4/epas/resources/sportpolicies_en.asp.

[7] Kasa, J. (2000). Sport Anthropomotorics (in Slovak): "Športová Antropomotorika", Bratislava Slovenská vedecká spoločnost' pre telesnú výchovu a šport, 209. s. ISBN 80968252-3-2.

[8] Kos, B., \& Štepnička, J. (1980). Gymnastics for Every Day (in Czech): “Gymnastika pro každý den”, OLYMPIA: Praha.

[9] Kurelić, N., Momirović, K., Stojanović, M., Šturm, J., Radovanović, Đ., Viskić-Śtalec, N. (1975). The structure and development of the morphological and motor dimensions of children and youth (in Serbo-Croatian): "Struktura i razvoj morfoloških i motoričkih dimenzija dece i omladine." Institut za naučna istraživanja Fakulteta za fizičko vaspitanje, Univerziteta u Beogradu.

[10] Horváth, R. (2002). The Dynamics of change in some somatic and motor predisposition in students of Pedagogy for the $1^{\text {st }}$ level of the Primary schools (in Slovak): "Dynamika zmien niektorých somatických a motorických predpokladov $u$ študentov učitel'stva pre I. stupeň ZŠ". Slovenská vedecká spoločnost' pre telesnú výchovu a šport. ManaCon, Prešov. ISBN 80-89040-16-0. 
[11] Moravec, R., Kampmiller, T., \& Sedláček, J. (2002). EUROFIT - Physique and Motor fitness of the Slovak school youth - Slovak Scientific Society for Physical Education and Sports - Bratislava. ISBN 80-89075-11-8.

[12] Pangrazi, R.. P. (2000). Promoting Physical Activity for Youth. Keynote Presentation from the 2000 Pre-Olympic International Congress on Sport Science Sports Medicine and Physical Education, Brisbane-Australia, 7-13 September, 2000. In: Journal of Science and Medicine in Sport, Volume 3, (3): 280-286, published by Sports Medicine Australia.

[13] Popović, R., et al. (2016). Rating of the physical fitness level in Physical Education female students using "Eurofit-Test", $19^{\text {th }}$ International Scientific Conference FIS Communications2016 in Physical Education, sport and recreation. In: Ed.: S. Pantelić: Book of Proceedings (pp. 233-245), Ministry of Education, Science and Technological Development-Serbia.

[14] Popović, R., Đoković, J., \& Popović, M. (2016). Estimation of the Motor Competence of PE female Students by applying Physical Fitness Test: Case study. The $3^{\text {rd }}$ International Conference "Anthropological and Theo-anthropological views on Physical Activity from the time of Constantine the Great to Modern Times" 23-27.03.2016. Kopaonik, Serbia, Book of abstracts, p.41. Fakultet za Sport i fizičko vaspitanje, Univerzitet u Prištini, FIEP Srbija i Asocijacija Sport za sve Srbije.

[15] Popović, R., \& Samouilidou, E. (2015). Identification the cross cultural differences of basic motor abilities status in home and foreign country physical education female students. In M. McGreevy, \& R. Rita (Eds.), Proceedings of the $3^{\text {rd }}$ CER Comparative European Research ConferenceInternational Scientific Conference for PhD students of EU Countries "CER 2015", Vol. 2, Issue 1 (pp. 172-175). March, 23-27, 2015, London (UK): Sciemcee Publishing. ISBN 978$0-9928772-6-2$

[16] Stojanović, D. (2016). Differences in the Physical Fitness of the students with different levels of the Cardio-RespiratoryEndurance (in Serbo-Croatian): "Razlike fizičkog fitnesa studenata sa različitim nivoima kardiorespiratorne izdržljivosti”, Glasnik Antropološkog društva Srbije (manuscript, in print).

[17] http://www.topendsports.com/testing/beepcalc.htm. 